\title{
Letters
}

\section{Waiting for radiotherapy}

\section{New initiatives may transform service}

EDITOR-Dodwell and Crellin analyse the problems of the current radiotherapy service in the United Kingdom. ${ }^{1}$ Some important initiatives are under way in England and Scotland to make the service workload sensitive.

Faced, in 2003, with Royal College of Radiologists audits ${ }^{2}$ and an Audit Commission report ${ }^{4}$ identifying a serious deterioration in waiting times for radiotherapy over the previous five years, the Department of Health in England created a standing multidisciplinary national radiotherapy advisory group. This has commissioned streams of work, particularly in estimating and delivering the predicted radiotherapy fraction demand for the next decade and providing flexible, mature staff to deliver it. The government has also sponsored a research project on extending the working day to try to learn from departments that have successfully used this manoeuvre. Initial reports will be available in the first half of 2006.

In Scotland, the health department has independently developed a useful model to estimate radiotherapy need on the basis of cancer incidence and a professional estimate of need based on international experience. ${ }^{5}$ This year's waiting list targets in the Department of Health's cancer plan for first cancer treatmentinitiation within 31 days from acceptance of the offer by the patient and within 62 days from urgent referral by

the general practitioner-seem to have galvanised managers to help departments reach target waiting times in $20-30 \%$ of patients.

Current evidence seems not to show that the creation of two radiotherapy waiting lists results in deteriorating waiting times for patients on the "other" list. The expansion of the service also seems likely to result in improved access to radiotherapy through the development of satellite radiotherapy units working to agreed standards to ensure that their service provision is equal to and integrated with the service in cancer centres. In addition, a new design of linear accelerator building can now be built in a few days rather than a year.
Only a failure of national political will, a collapse in national funding for NHS development, or a failure of ministers to resolve the current funding system for this strategic service can stand in the way of the United Kingdom having an efficient workload sensitive service for the NHS patients of the next decade.

Robin D Hunter dean of faculty

Faculty of Clinical Oncology, Royal College of Radiologists, London W1B 1JQ robin_hunter@rcr.ac.uk

Competing interests: None declared.

1 Dodwell D, Crellin A. Waiting for radiotherapy. BMJ 2006;332:107-9. (14 January.)

2 Ash D, Barrett A, Hinks A, Squire C. Re-audit of radiotherapy waiting times 2003. Clin Oncol 2004;16:38794.

3 The Royal College of Radiologists. A national audit of waiting times for radiotherapy. London: Royal College of Radiologists, 1998.

National Audit Office. Tackling cancer in England: savin more lives. London: National Audit Office, 2004.

5 Erridge SC, Chalmers R, Featherstone C, et al. How many ractions of radiotherapy will be required for Scotland in 2015? Clin Oncol 2005;17:s13-14.

\section{Financing increased capacity is a must}

EDITOR-Dodwell and Crellin's points about the issues facing radiotherapy services are V $\begin{aligned} & \text { starting to apply to the } \\ & \text { services that administer }\end{aligned}$ chemotherapy and other parenteral drug treatments for cancer. ${ }^{1}$

The number of patients requiring such treatments for cancer is rising, as the baby boom generation ages and as the $\frac{1}{2}$ recently reported evidence that treatment with Hercepin (trastuzumab) every three weeks for at least 12 months markedly reduces the recurrence rate for breast cancer is a topical case in point. ${ }^{2}$ These treatments require specialist nurses operating from appropriate premises, with a pharmacy service able to supply medicines prepared to the required standards. The processes by which increased demand with inadequate capacity in these resources results in a service that is degraded by delay are similar to those described by Dodwell and Crellin.

The only patients with cancer to benefit in the competition for these resources by virtue of a national target are those for whom this treatment is the first modality to be applied; their treatment must start within 62 days of diagnosis. This group is not necessarily the one with the highest clinical priority; palliative treatment for recurrent disease needs to start promptly to relieve symptoms and post-surgical adjuvant treatment needs to start promptly to minimise recurrence.

The only way to deal with this is to finance increased capacity. The present state of commissioning finances in the NHS seems absolutely to preclude these developments.

S Michael Crawford consultant medical oncologist Airedale General Hospital, Keighley, West Yorkshire BD20 6TD michael.crawford@anhst.nhs.uk

Competing interests: SMC leads a district general hospital oncology service, in which the initiation of treatment is increasingly subject to delay because of capacity issues.

1 Dodwell D, Crellin A. Waiting for radiotherapy. $B M J$ 2006;332:107-9. (14 January)

2 Piccart-Gebhart MJ, Procter M, Leyland-Jones B, Goldhirsch A, Untch M, Smith I, et al. Trastuzumab after adjuvant chemotherapy in HER2-positive breast cancer. N Engl J Med 2005;353:1659-72.

\section{Introducing new health interventions}

\section{Diagnostics is the Cinderella of health technology assessment}

EDITOR-The several papers on evaluating new healthcare interventions omit any mention of a crucial sector of health care: diagnostics. $^{1-3}$ The National Institute for Health and Clinical Excellence (NICE) shares this blindspot.

The importance of diagnostics has recently been highlighted by the sudden introduction of Herceptin (trastuzumab) treatment for all women with breast cancer who could benefit. Quality controlled laboratory assessment of HER2 status, essential to define those who could benefit, was not adequately considered and serious problems resulted.

The problem is being exacerbated by the advances of molecular biology. For example, a paper in last month's Journal of Pathology argues cogently that all new colorectal cancers should be tested for DNA mismatch repair deficiency. ${ }^{4}$ So should NHS pathology laboratories all be doing this? Perhaps not yet-the very next paper in the same issue illustrates quality control problems with this investigation.

A systematic and authoritative approach to evaluating new diagnostic tests is lacking, but it is needed just as much as a system for 
evaluating new drugs and procedures. Currently, whether patients can benefit from new diagnostic modalities is a "postcode lottery."

Peter N Furness consultant histopathologist Leicester General Hospital, Leicester LE5 4PW pnf1@leicester.ac.uk

Competing interests: FNP is an NHS diagnostic histopathologist.

1 Gabbay J, Walley T. Introducing new health interventions. BMI 2006;332:64-5. (14 January.)

2 McDonnell A, Wilson R, Goodacre S. Evaluating and implementing new services. BMJ 2006;332:109-12. (14 January.)

3 Wilson CB. Adoption of new surgical technology. BMJ 2006;332:112-4. (14 January.)

4 Ward R L, Turner J, Williams R, Pekarsky B, Packham D, Ward R L, Turner J, Williams R, Pekarsky B, Packham D,
Velickovic M, et al. Routine testing for mismatch repair Velickovic M, et al. Routine testing for mismatch repair
deficiency in sporadic colorectal cancer is justified.J Pathol deficiency in spora
2005;207:377-84. 5 Mangold E, Pagenstecher C, Friedl W, Fischer HP, Merkelbach-Bruse S, Ohlendorf M, et al. Tumours from MSH2 mutation carriers show loss of MSH2 expression but many tumours from MLH1 mutation carriers
exhibit weak positive MLH1 staining. J Pathol 2005;207: exhibit weak.

Some initial risk taking is essential in adopting new surgical technology

Editor-The article by Wilson on the adoption of new surgical technology raised an aspect of innovation that is not often considered-the psyche of the medical team adopting new technology. ${ }^{1}$ However, the author betrays an underlying assumption that all innovators are the swashbuckling type and keen to try the latest fashion. Today an unhealthy emphasis on safe, rather than efficient, surgical practice and target driven care for patients have served to ensure that all new technology is guilty until proved innocent and all innovation suspicious.

Some initial risk taking and openness to new technology is essential to determine efficacy and cost effectiveness in a prescribed format later. A comparison of the time taken to bring a new technique to the clinic now and 50 years ago would be interesting. I think that the $20 \%$ critical mass quoted by Wilson would have been reached much sooner in an earlier era.

Successful technology is subject to greater scrutiny at a later stage than technologies that are abandoned early by their innovators, thereby introducing a selection bias.

Vinay P Rao research fellow

Mayo Clinic, Rochester, MN 55905, USA

vinayprao@yahoo.com

Competing interests: None declared.

1 Wilson CB. Adoption of new surgical technology. BMJ 2006;332:112-4. (14 January.)

\section{Underfunding of primary care in deprived areas affects everyone}

EDITOR-The paper by McColl et al and the accompanying editorial raise important questions about the provision of primary care in areas with high levels of deprivation. ${ }^{12}$ It is misleading to focus on refugees and asylum seekers as it suggests that the only problem is one of discrimination against this group-although there may be some truth in this assertion, the reality is far more complex. Accessing primary care is a problem for all residents of Tower Hamlets and, by extrapolation, for those in other areas with similar populations.

This is nothing new-such communities have always been comparatively underresourced. But what has changed is the clamour for increased quality of service provision and increased levels of access at the same time as there has been a shift of work from secondary to primary care. Primary care trusts, in contrast, find themselves in the unenviable position of having to cajole general practitioners into quantifiable action while being squeezed by the Department of Health to deliver increasingly unrealistic targets.

Meanwhile primary health care teams grapple with recruitment and retention and, at full capacity, struggle to balance service delivery from their inadequate premises when there is little hope of improvement.

In this climate, it is small wonder that registration with primary care is problematic. If Project: London effectively highlights this issue and greater funding comes our way, fine, but the reality is that greater pressure will be exerted on the same workforce and that there will be no extra public service investment.

James N Hardy general practitioner principal Bethnal Green Health Centre, London E2 6LL james.hardy@nhs.net

Competing interests: $\mathrm{JH}$ is a general practitioner in Tower Hamlets.

1 McColl K, Pickworth S, Raymond L. Project: Londonsupporting vulnerable populations. BMJ 2006;332:115-7. (14 January.)

2 Hull SA, Boomla K. Primary care for refugees and asylum seekers. BMJ 2006;332:62-3. (14 January.)

\section{Gastro-oesophageal reflux disease}

\section{Surgery is an alternative}

EDITOR-Gastro-oesophageal reflux disease, being increasingly common, is a huge problem, and prescribing of proton pump inhibitors is a large burden on the NHS. Fox and Forgacs mentioned surgical management towards the end of their article, ${ }^{1}$ but we disagree with the implication that antireflux surgery is limited to those patients in whom medical management is either ineffective or poorly tolerated. For patients who do not want to remain dependent on daily drug treatment it may simply be an alternative treatment, a lifestyle choice.

Also not mentioned was our recent randomised controlled trial of laparoscopic Nissen fundoplication $v$ proton pump inhibitors, carried out in the United Kingdom. ${ }^{2}$ This gave results favouring surgical fundoplication. It was accompanied by our economic analysis, ${ }^{3}$ which shows that surgical management, in the long term, is the more cost effective solution. This is an important consideration in today's NHS.

David Mahon specialist registrar general surgery

North Hampshire Hospitals NHS Trust,

Basingstoke RG24 9NA

bmj@amigo.co.uk

Michael Rhodes consultant surgeon

Norfolk and Norwich University Hospital, Norwich NR4 7UY

Competing interests: The authors' research was funded by Janssen Pharmaceuticals and Ethicon Endosurgery.

\section{Fox M, Forgacs I. Gastro-oesophageal reflux disease. $B M J$ 2006;332:88-93. (14 January.) \\ 2 Mahon D, Rhodes M, Decadt B, Hindmarsh A, Lowndes R, Beckingham I, et al. Randomized clinical trial of laparoscopic Nissen fundoplication compared with proton-pump inhibitors for treatment of chronic gastro- oesophageal reflux. Br J Surg 2005;92:695-9. \\ 3 Cookson R. Flood C. Koo B. Mahon D. Rhodes M. Short-term cost effectiveness and long-term cost analysis comparing laparoscopic Nissen fundoplication with proton-pump inhibitor maintenance for gastro- oesophageal reflux disease. BrJ Surg 2005;92:700-6.}

\section{Posture is important}

EdiTor-Fox and Forgacs do not mention the effects of posture on gastro-oesophageal reflux disease in their review. ${ }^{1}$ Controlled trials are not possible in this respect, but some weight must be given to the experience of many patients and doctors.

I can report on over 70 years of coming to terms with peptic ulceration and over 30 years of trying to cope with severe reflux. Gross adverse reactions to the modern acid suppressants as well as clarithromycin have forced me to rely on a postural approach, which is effective when combined with a simple antacid mixture taken after meals and at bedtime. Patients should be advised to avoid bending down, especially after meals. They should be encouraged to sleep in a semi-upright position.

This is achieved ideally by the use of an adjustable mattress, but such beds are expensive and not transportable. A backrest is easily improvised, but a "donkey" is required behind the knees to prevent sliding down the bed. Traditionally, a bolster has been used for this purpose. To prevent it rolling down the bed, it has to be wrapped in a drawsheet with its ends tucked under the mattress on each side. This works well but may be too awkward to take on holiday.

A portable, inflatable plastic bolster is needed. Were it to be coated with, or wrapped in, a material with a suede finish the friction generated would stop it from sliding. I have improvised cushions of this type with success, but some manufacturing problems have to be overcome.

Norman K Gibbon retired consultant urologist

Liverpool L37 2EY

nok-gibbon@mersinet.co.uk

Competing interests: None declared.

1 Fox M, Forgacs I. Gastro-oesophageal reflux disease. BMJ 2006;332:88-93. (14 January.) 


\section{When to test women for human papillomavirus}

Testing is possible without increasing colposcopy referral rate

Editor-Moss et al show that colposcopy referral rates double if women with equivocal or mild cytological abnormality are referred for immediate colposcopy when human papillomavirus (HPV) is present in the first abnormal smear. ${ }^{1}$ Their colposcopy rates in women aged 35-64 seem to contradict those observed in the Netherlands.

We computed colposcopy referral rates in the Netherlands from data collected in the two armed POBASCAM screening trial. ${ }^{2}$ Women of 30-60 with borderline or mild dyskaryosis were recalled at 6 and 18 months and referred for colposcopy on the basis of repeat cytology according to current Dutch guidelines (control group) or on the basis of both repeat cytology and high risk HPV testing (intervention group).

In the control group $18.9 \%$ of all women with borderline dyskaryosis at baseline and $51.0 \%$ of those with mild dyskaryosis were eventually referred for colposcopy. After correction for loss to follow-up, we obtained adjusted colposcopy rates of $29.3 \%$ and $68.1 \%$ and rates of repeat smears per woman of 1.80 and 1.50 for women with borderline and mild dyskaryosis respectively.

The tabulated colposcopy referral rates in the control group are twice as high as the before pilot referral rates presented by Moss et al for women aged 35-64, whereas only a small increase in the rate of repeat smears is observed. Moreover, the colposcopy referral rates in the control and intervention group of the POBASCAM trial were similar, indicating that HPV testing in the intervention group did not lead to increased colposcopy rates.

The large difference in referral rates in the United Kingdom and the Netherlands for strategies with repeat cytology may be partly explained by the difference in referral policy and follow-up period. Hence, comparability between the referral rates may improve when referral rates are reassessed after a longer follow-up

On the basis of recent cost-effectiveness calculations, ${ }^{3}$ we advise to return HPV negative women with a borderline or mildly dyskaryotic smear immediately to routine screening or to manage such women by repeat cytology and HPV testing at 6 and 18 months without HPV testing at baseline. Regarding the second strategy, women who test negative on both tests at the first or second recall are immediately returned to routine screening. If we project the second strategy on the POBASCAM data, colposcopy referral rates of $24.3 \%$ and $59.4 \%$ and repeat smear rates per woman of 1.08 and 1.17 are obtained in case of borderline and mild dyskaryosis, respectively. These data indicate that high risk HPV testing can be implemented in triage policies for women with equivocal or mild cytological abnormalities in such a way that the number of repeat smears is markedly reduced without the cost of an increase in colposcopy referral rate.

Johannes Berkhof assistant professor h.berkhof@vumc.nl

Folkert J van Kemenade $P h D$

Peter J Snijders $P h D$

René $\mathbf{H}$ Verheijen professor

Chris J Meijer professor

Department of Clinical Epidemiology and

Biostatistics, VU University Medical Centre, 1007 MB Amsterdam, Netherlands

Competing interests: None declared.

1 Moss S, Gray A, Legood R, Vessey M, Patnick J, Kitchene H. Effect of testing for human papillomavirus as a triage during screening for cervical cancer: observational before and after study. BMJ 2006;332:83-5. (14 January.)

Bulkmans NW, Rozendaal L, Snijders PJ, Voorhorst FJ, Boeke AJ, Zandwijken GR, et al. POBASCAM, population-based randomized controlled trial for implementation of high-risk HPV testing in cervical screening: design, methods and baseline data of 44,102 women. Int Cancer 2004;110:94-101.

3 Berkhof J, de Bruijne MC, Zielinski GD, Bulkmans NW Rozendaal L, Snijders PJ, et al. Evaluation of cervica screening strategies with adjunct high-risk human papillomavirus testing for women with borderline or mild dyskaryosis. Int J Cancer 2005 Oct 10; PMD 16217759 (Epub ahead of print).

\section{Take this opportunity to screen for anal} cancer too

EDITOR-The impact of screening for human papillomavirus (HPV) on the rates of cervical intraepithelial neoplasia is topical. ${ }^{1}$ The introduction of routine cytological screening has reduced the incidence of cervical cancer.

Despite obvious similarities, anal cancer has not been given the same 83 level of attention. There are no guidelines regarding screening. The incidence of anal cancer has increased by almost $40 \%$ in women. ${ }^{2}$ A $26 \%$ genotypic concordance toxists among concurrent HPV infections of the cervica and anal canals, indicating a common source of infection, such as vaginal and anal intercourse with the same infected partner(s). ${ }^{3}$ Women with cervical infection have three times the risk of anal infection, and up to $13 \%$ will be infected at both sites. ${ }^{3}$ In the anus, however, non-oncogenic strains predominate. This may explain the lower prevalence of anal compared with cervical cancers.

This, however, does not detract from the fact that young healthy women, infected with HPV 16 and 18, with a regular consumption of alcohol, a history of chlamydial infection, early age of sexual intercourse, and several lifetime sexual partners are at risk of cervical infection.

These may be the risk factors that point to anal cancer. HIV infection and immunosuppression further increase this risk. ${ }^{2}$ It may be prudent to use these in establishing guidelines for anal cancer screening, particularly with the growing indication that the two entities may share a common aetiology.

Awori J Hayanga general surgery resident University of Michigan Health Systems jhayanga@med.umich.edu

Competing interests: None declared.
1 Legood R, Gray A, Wolstenholme J, Moss S. Lifetime effects, costs, and cost effectiveness of testing for human papillom, virus to manage low grade cylogical abo (14 J Che

Chang GJ, Berry M, Jay N, Palefsky, JM, Welton ML. Surgical treatment of high-grade anal squamous intraepithelia Apr:45(4):453-8

, Herilkens LR, Killeen J, Kesse B, et , McDuffe K, Zhu X, Wikens LR, Killeen J. Kesse B, et al. Anal human papillomavirus infection in Epidemiol Biomarkers Prev 2005;14(11 Pt 1):2550-6.

\section{Incapable patients and the law}

EDITOR-Stewart writes that patients with dementia can be judged to be lacking capacity by a single medical opinion and transferred to an institutional facility "in their best interests," with little chance of being able to leave and little or no access to appeal. ${ }^{1}$ The law says that shouldn't happen, and in time, there will be legislation to prevent it.

In the Bournewood case, the European Court of Human Rights said that where best interests was used to deprive incapable patients of their liberty, it breached article 5 of the European Convention on Human Rights. The court did that at least partly for the reason Stewart mentions: the lack of an effective right of appeal.

The best interests justification is, of course, a product of the common law doctrine of necessity. Although the fact that the doctrine can breach the European convention is not mentioned by Doyal and Sheather, ${ }^{2}$ it is certainly exercising the government at the moment. There is to be a new framework of rights for incapable patients and a process to be followed if they are to be deprived of their liberty. ${ }^{3}$

The precise form of the new framework is yet to be announced. It might be included in the next Mental Health Act or into the Mental Capacity Act. The question of what should be done in the interim is both troubling and contentious.

In the case of incapable patients who are, in effect, being deprived of their liberty, the only way to protect their rights seems to be to detain them under the Mental Health Act. That, at least, is the view of the Mental Health Act Commission.

However, there may be some incapable patients who do not meet the criteria for compulsory admission. This is particularly so when such patients are confined, not because of their mental state or behaviours, but so they can have orthopaedic surgery, for example, or be seen in accident and emergency. Bournewood applies with equal force to them.

David W Hewitt partner

Hempsons Solicitors, Manchester M1 3LF dwh@hempsons.co.uk

\section{Competing interests: None declared.}

Stewart R. Mental health legislation and decision making capacity. BMJ 2006;332:118-9. (14 January.)

Doyal L, Sheather J. Mental health legislation should Doyal L, Sheather J. Mental health legislation should
respect decision making capacity. BMJ 2005;331: 1467-71. (17 December.)

3 Department of Health. 2005. "Bournewood" consultation; the approach to be taken in response to the judgment of the European Court of Human Rights in the "Bournewood" case. London:

4 Mental Health Act Commission. In place of fear? Eleventh biennial report 2003-2005. London: Mental Health Act Commission, 2006:para 3.7. 


\section{Management of Clostridium difficile in NHS trusts}

EDITOR-A recent report and press statement by the Healthcare Commission and Health Protection Agency (HPA) say that a third of NHS trusts are not adhering to government guidance on the prevention and control of Clostridium difficile infection. ${ }^{12}$ In parallel, the chief medical and the chief nursing officers have written a joint letter to trusts' chief executives. ${ }^{3}$ The letter says that guidance published in 1994 by the Department of Health and the then Public Health Laboratory Service (now the HPA) is "current." I telephoned the publication department of the Department of Health for a copy, only to be told it does not have anything that goes back "that far." A similar request to the HPA also drew a blank.

The report advises trusts have antibiotic prescribing guidelines to reduce the risk of $C$ difficile infection. ${ }^{1}$ However, the supporting reference given was a report made to, rather than guidance from, the Department of Health, which included the findings of the national standards group for $C$ difficile, ${ }^{5}$ an expert group established at the request of the Department of Health to review evidence pertaining to the diagnosis and control of $C$ difficile associated diarrhoea and to make recommendations for developing the surveillance system. This group made several recommendations to the department, but despite their report being nearly three years old and surveillance now in place, no updated guidance on prevention and control has been issued. What guidance is it that trusts are not adhering to and whose advice should be followed in the future?

The press release from the Healthcare Commission and HPA focuses exclusively on the negative findings of the report, ${ }^{12}$ and findings that $89 \%$ of trusts have a written policy that covers the management of infection from $C$ difficile have therefore gone unreported in the media. If trusts are to reduce the incidence of infection from $C$ difficile a useful starting point is guidance contained in a single document that is both current and accessible.

David Green lead nurse infection control Bradford Royal Infirmary, Bradford BD9 6RJ david.green@bradfordhospitals.nhs.uk

\section{Competing interests: None declared.}

1 Health Protection Agency, Healthcare Commission, Management, prevention and surveillance of Clostridium diffi-
cile: interim findings from a national survey of NHS acute trusts in England. 21 December 2005. www.hpa.org.uk trusts in England. 21 December 2005 .
infections/topics az/clostridium difficile/ infections/topics_az/clostridium_difficie/

2 Healthcare Commission Press Release, Healthcare agencies urge the NHS to step up measures to minimise risk of patients contracting Clostridium difficile. 21 December patients contracting Clostridium difficile. 21 Decembe 2005. www.healthcarecommission.org.uk/NewsAndEvents/
PressReleases/PressReleaseDetail/fs/en?CONTENT ID = 4022047\&chk $=$ n0pJM $/($ accessed 20 Jan 2006).

3 Chief Medical Officer and Chief Nursing Officer's Letter. Chief Medical Officer and Chief Nursing Officer's Letter. Infection caused by Clostridium difficile. 21 December 2005. PL CNO/2005/6, PLCNO2005/5. www.dh.gov.uk/ PublicationsAndStatistics/LettersAndCirculars/Professional Letters/ChieANursingOfficerLetters/ChiefNursingOfficer LettersArticle/s/en?CONIEN_L $=4124989 \&$ chk $=$ fjm $0 \mathrm{cF}$ (accessed 20 Jan 2006)

4 Clostridium difficile infection: prevention and management. A report by a Department of Health/PHLS joint working group. d, Manchester: BAPS Health Publications Unit, 1994. 5 Public Health Laboratory Service Communicable Disease
Surveillance Centre. National Clostridium difficile standards
group report to the Department of Health. London: PHLS,
February 2003 .

\section{Research governance}

Research governance approval is putting people off research

EDITOR-The BMJ has highlighted the bureaucratic burden placed on health researchers by the research governance approval process. ${ }^{12}$ Our own study sought only to interview health professionals in 12 trusts about giving advice, with a few patient telephone interviews, but the process of seeking approval from one research and development consortium delayed our project by 11 weeks.

If this sort of approval process does not put researchers off, then the procedure for gaining honorary contracts surely will These contracts are apparently a necessary requirement for everyone conducting research in the NHS-even NHS staff if they are collecting data from NHS trusts other than the one that employs them. Unbelievably, even when one of us already held an NHS honorary contract with one trust, another honorary contract had to be issued by the same trust (with accompanying delays) because the previous one was linked to a different project.

Many trusts also require an occupational health check and proof of immunisation to various diseases-even for researchers who will have no contact with patients. This further administrative hurdle can take months to overcome, but it is not the last.

Many trusts now insist that honorary contracts are accompanied by a Criminal Records Bureau check, which can take several months. We protested that these checks aimed to protect vulnerable adults were unnecessary. But, astonishingly, even our simple interviews with health professionals were forbidden until after the checks and honorary contracts were issuedanother two month delay. To make matters worse, one research and development department failed to initiate the process for at least two weeks and only realised its mistake after yet another inquiring phone call from us. Eventually, after even more protesting emails and phone calls (including one from our government funders, who were incredulous at the delay), we were given the go-ahead to speak to health professionals, without needing honorary contractsbut not before research governance approval had been formally agreed.

The research governance approval system should be revised before more health researchers change careers.

Niall Galbraith research fellow

n.d.galbraith@warwick.ac.uk

Carol Hawley principal research fellow

Valerie De-Souza research fellow

Division of Health in the Community, Warwick

Medical School, University of Warwick, Coventry

CV4 7AL

Competing interests: None declared.
1 Elwyn G, Seagrove A, Thorne K, Cheung W Y. Ethics and research governance in a multicentre study: add 150 days o your study protocol. BMJ 2005;330:847.

2 Warlow C. Clinical research under the cosh again. $B M J$ 2004:329:241-2.

\section{Whose idea is it?}

EDITOR-In the previous letter Galbraith et al identify a further major obstacle and hindrance- - the procedures for gaining honorary contracts required by all those conducting research in the NHS. ${ }^{1}$

As a voluntary, independent, self employed individual patient-researcher, I have been a steering group patient member in various research projects at different institutions since 1995. In November 2005 I received from a university research and commercial division "duplicate originals" of a formal agreement for signature for participation as a steering group member in a Department of Health funded project to undertake a systematic review. To say that the requirements were onerous understates the case.

Public involvement in research is encouraged, indeed stipulated by the Department of Health and related research commissioning bodies. The National Cancer Research Institute and National Cancer Research Network have defined the practicalities of involving members of their consumer liaison group in research. This includes setting out in detail, for example, how honorariums and other payments for attendance at meetings on behalf of these institutions should be made.

The research governance approval system obstructs and delays research unnecessarily: this is unethical and ultimately reduces patients' length and quality of life. The new professionalism that is being encouraged in the Royal College of Physicians' report calls for a responsible engagement that draws in a well informed public alongside the medical profession. ${ }^{2}$ Where better than to start here? Testing treatments should be everyone's business. ${ }^{34}$

Hazel Thornton independent advocate for quality in research and healthcare

Rowhedge, Colchester CO5 7EA

hazelcagct@keme.co.uk

Competing interests: None declared.

1 Elwyn G, Seagrove A, Thorne K, Cheung WY. Ethics and research governance in a multicentre study: add 150 day to your study protocol. BMJ 2005;330:847

2 Report of a Working Party. Doctors in society. Medical professionalism in a changing world. London: Royal College of Physicians, 2005.

3 Evans I, Thornton H, Chalmers I. Testing treatments. Better research for better healthcare. London: British Library (in press). 4 Chalmers I, Silverman WA. Professional and public double standard on clinical experimentation. Control Clin Trials $1987 ; 8: 388-91$

\section{bimj.com}

We select the letters for these pages from the rapid responses posted on bmj.com within five days of publication of the article to which they refer.

Letters are thus an early selection of rapid responses on a particular topic. Readers should consult the website for the full list of responses and any authors' replies, which usually arrive after our selection. 